\title{
Misconceptions about falling sperm counts and fertility in Europe
}

\author{
Egbert R te Velde ${ }^{1,2}$ and Jens Peter Bonde ${ }^{3}$ \\ Asian Journal of Andrology (2013) 15, 195-198; doi:10.1038/aja.2012.122; published online 3 December 2012
}

\begin{abstract}
T he Science Policy Briefing on male 1 reproductive health published by the authoritative European Science Foundation (ESF) in 2010 echoes the views expressed in the famous paper by Carlsen et al., suggesting that mean sperm counts decreased by $50 \%$. The authors are convinced that the male reproductive system in industrialized countries is under attack from environmental chemicals. This may have farreaching consequences for the reproductive capacity of future generations. Their arguments, however, contain some misconceptions about declining sperm quality and fertility. Although there is reason for concern about the effect of environmental pollution, the authors' pessimism is not justified.
\end{abstract}

The authoritative ESF aims to provide a common platform to advance European research collaboration and explore new directions for research improving the wellbeing of European citizens. To this end, so-called Science Policy Briefings are regularly published. The September 2010 issue is entitled Male Reproductive Health-Its Impact in Relation to Gneral Wellbeing and Low European Fertility Rates. ${ }^{1}$ The chief executive of ESF and the chairman of the European Medical Research Council write in their foreword: 'This Science Policy Briefing is the first to highlight this important issue which could have a dramatic impact on future birth rates and demographic changes in industrialised countries'.

Apparently, the authors of this Policy Briefing - six renowned experts in the field of toxicology, reproductive biology and ${ }^{1}$ Department of Public Health, Erasmus University MC, Rotterdam, GE 3015, The Netherlands; ${ }^{2}$ Reproductive Medicine, Utrecht University, Utrecht, CM 3584, The Netherlands and ${ }^{3}$ Department of Occupational and Environmental Medicine, Bispebjerg Hospital, University of Copenhagen, Copenhagen, NV 2400, Denmark

Correspondence: Dr ER te Velde (e.r.tevelde@ziggo.nl)

Received: 1 September 2012; Revised: 12 October 2012; Accepted: 15 October 2012; Published online: 3 December 2012 environmental pollution-are convinced that the male reproductive system in industrialized countries has been and still is under attack by environmental chemicals. The decline in sperm quality and the increasing prevalence of genito-urinary abnormalities such as testicular cancer, cryptorchidism and hypospadias are part of the so-called 'testicular dysgenesis syndrome' which has a common environmental aetiology and is caused by in utero exposure to high levels of 'endocrine disrupting chemicals'. The authors believe that these perturbing exposures may have far-reaching consequences for the reproductive capacity of future generations, the first signs of which are already apparent. To preclude disaster, extensive, international researches followed by preventive actions are mandatory.

Surprisingly, this policy briefing on male reproductive health contains some misconceptions and fallacies about declining sperm quality and fertility. Apart from scientific arguments, strong beliefs seem to play a role in the discussion of whether or not male reproductive health is at risk in Europe. The contents and arguments used in the report lean heavily on the work of the corresponding author and his Danish research group. This policy briefing is in fact a concise outline of the views and concepts of their research as published in numerous papers. Hence we use some characteristic passages as the starting-point of the misconceptions discussed. First we will give some background information on reproduction, fecundity and fertility.

\section{REPRODUCTION, FECUNDITY AND FERTILITY: WHAT IS THEIR RELATIONSHIP AND HOW ARE THEY DEFINED?}

Reproduction depends on the subtle balance between success and failure of complex, mostly poorly-understood sequential processes that may lead to a pregnancy and to the birth of a child. ${ }^{2}$ These processes include spermatogenesis and oogenesis, sexual intercourse and transport of gametes, the penetration of the sperm cell through the zona pellucida of the oocyte followed by its fertilisation, migration of the embryo to the uterus and its subsequent implantation, the intrauterine development of the foetus and eventually the birth of a child. Failure can occur at any link of this delicate chain but most commonly does so at the early stages. From this description, it is obvious that reproduction is a matter of refined interactions between a male and female individual and that fecundity - the ability to conceive and have children-depends on numerous largely unknown male and female factors. The degree of fecundity of a couple is determined by the chance per menstrual cycle of a conception leading to live birth, so-called 'fecundability'. The distribution of individual couple chances is extremely heterogeneous, varying from zero (sterile) to an estimated upper limit of $60 \%$ per menstrual cycle ('super fertile'). ${ }^{3-5}$ Since the most fecund couples will conceive first, progressively fewer and less-fecund couples remain in the pool of couples who have not (yet) achieved a pregnancy as time goes by. Hence, the time it takes to become pregnant since actively trying to conceive-time to pregnancy-is an often used and sensitive measure of couple fecundity. The mean time to pregnancy of a population of couples trying to become parents has been extensively used in epidemiological studies to assess risk factors, differences between regions and trends over time. ${ }^{6-9}$

What about male and female fecundity? The problem is that neither are separately assessable, being always dependent on the interaction between the partners. For 
example, even a rather serious male fertility problem can be compensated for by a 'super fertile' partner and it then remains unnoticed. ${ }^{5}$ Since only couple fecundity is measurable, markers of e.g. sperm quality and menstrual cycle characteristics can only be considered as proxy measures of couple fecundity.

Furthermore, it is important to realize that the term 'fertility' in reproductive medicine and in common language has the same meaning as the demographic term 'fecundity': the ability to conceive and have children, given unprotected intercourse. In the demographic terminology, however, fertility and infertility are purely descriptive terms denoting the number of children that women have during a certain period of time, irrespective of their intentions. ${ }^{10}$ For example, a couple has been fertile in the first 3 years of marriage if at least one live birth has been recorded during those years, whereas if no birth ensued, the couple is recorded as infertile, irrespective of whether contraception was used to prevent a pregnancy. Likewise, the total fertility rate (TFR, also called period TFR) is an often used demographic term denoting the average number of children per calendar year that would be born if women were to continue to experience the current age-specific fertility rates. As they usually get more children, this measure mostly underestimates the cohort TFR, which is the mean total number of children that women eventually will have. In contrast to cohort TFR, the period TFR is very sensitive to political and economic change. For example, the results of a recent paper indicate that in times of economic recession as ours, period TFRs often show a (probably temporary) declining trend. ${ }^{49}$

\section{MISCONCEPTIONS}

\section{'Semen quality has been declining throughout the past half century'}

This statement is based on the results of a much cited meta-analysis, demonstrating that mean sperm counts decreased by $50 \%$ during that period. ${ }^{11}$ This report has elicited the current debate between supporters and opponents. The controversy is related to the fact that the 61 retrospective studies included in the meta-analysis are extremely heterogeneous in terms of duration of abstinence, age, reasons for selection, socio-economic background, methods and quality assurance of semen analysis, lifestyle variables, demographic characteristics, seasonality and uncertainty about the comparability of the study populations from different time periods. ${ }^{12} \mathrm{~A}$ major problem for the interpretation of the results is caused by the large geographical differences in sperm counts. Therefore, the same research group that published the Carlsen paper ${ }^{11}$ initiated a prospective, still-continuing project in 1996 to monitor semen quality of young Danish men who attended a compulsory examination of fitness for military service. They were encouraged to provide semen samples and a total of $\sim 5000$ men did. The results demonstrate that median values remained around 40-45 million spermatozoa per $\mathrm{ml}$ throughout these 15 years and did not display a declining trend. Noticeably, these results had not been published by the initiators of this study in or by $2010 .^{13,14}$ Such prospectively collected data from a well-defined source population and examined according to the same, high-quality laboratory protocol offer a much better basis for evaluation of trends over time than retrospective data, in spite of the fact that participation rates were low over the years. While the Danish data have been corroborated by a smaller Swedish study, ${ }^{15}$ similar data from Finland over a shorter period are more difficult to interpret. ${ }^{16,17}$ Although the since-1996 prospectively collected figures from Denmark do not reflect semen quality in the preceding years, it seems highly unlikely that a decline in sperm counts would finish in the year when a large monitoring program with a perfect study design is started. Curiously, the authors of the 2010 Male Reproductive Health Policy Briefing report write 'Semen quality has been declining throughout the past half century in industrialised countries', while they must have been aware of the fact that this was not the case in part of Denmark during the last 15 years, and in Southern Sweden during the last decade. In a report on this subject 2 years later, these figures are also not mentioned and the notion of 'apparent decline in reproductive health' is still emphasized. ${ }^{18}$

'Declining male reproductive health could have a dramatic impact on future birth rates and demographic changes in industrialised countries'. 'It has been estimated that more than $7 \%$ of all children born in 2007 in Denmark were conceived by assisted reproductive technologies (ART)'

These statements are based on the suggestion put forward several times in different wording, namely that the declining birth rates in Europe may be partly caused by declining population fecundity as a consequence of deteriorating male reproductive health.

In fact, many trends and developments, both positive and negative, may have an impact on population fecundity. For example, increased fertility awareness may have resulted in more efficient use of the coital act during the fertile period of the menstrual cycle ${ }^{19}$ or may have encouraged couples to try 'more persistently'. ${ }^{20}$ Moreover, changes in lifestyle, such as a decrease in the frequency of smoking and a decline in the penalties of sexually transmitted diseases and the growing availability of effective ART such as in vitro fertilisation (IVF) and intracytoplasmic sperm injection may have changed population fecundity in a favourable direction. $^{21,22}$ In contrast, the postponement of parenthood to ages when not only women but also men become less fertile, ${ }^{23,24}$ and the growing epidemic of obesity ${ }^{25}$ must have had a negative impact on population fecundity. It is impossible to assess the impact of each of these trends separately. However, on the basis of various population studies on secular trends in fecundity in Europe and the United States, it is possible to get an impression about the net result of all these trends on population fecundity. Although subject to criticism, ${ }^{26}$ these studies demonstrate that population fecundities in different countries have not decreased over the past $30-40$ years. ${ }^{19-21,27-30}$ 'If one or more chemicals are relevant, either there has been no adverse impact in male fecundity during this period, or any such effect has been more than compensated by a countervailing increase in couple fecundity', one of the authors summarizes in his conclusion. ${ }^{19}$ A recent review on fertility trends in Scandinavian countries also concludes that neither semen quality nor fecundity seems to have declined during the last decade in the Nordic countries. ${ }^{31}$

Declining birth rates can be explained by social and demographic trends related to the contraceptive revolution of the 1960s, female emancipation and the second demographic transition. ${ }^{32,33}$ These societal developments also explain the fact that birth rates in some well-developed European Union (EU) countries reversed from a declining to a rising trend over the last decades. ${ }^{34}$ In Denmark, for example the TFR rose from the lowest level of 1.38 children in 1983 to 1.89 children per woman in 2008-a rise of 0.51 resulting in a cohort TFR which almost equals the replacement level. ${ }^{35}$ The results of a recent study published in Nature demonstrate that this rise is correlated with the human development index used by the United Nations Development Program. ${ }^{36}$ This measure combines indicators of economic and social development. Above a certain human development index threshold, TFRs in EU 
countries started to rise after decades of decline. The TFR increase is particularly high in Scandinavian countries as their human development indexes belong to the highest in Europe. Undoubtedly, the use of ART has contributed to this trend, but its impact is smaller than often claimed. Even when assuming that all children born after ART would never have been born because their parents were completely sterile, the contribution of ART would account for $0.14(7 \%)$ of the present cohort TFR, only explaining a fraction of the recorded TFR rise of $0.51 .{ }^{34}$ However, many couples with unexplained, mild or moderate subfertility may resort to ART sooner than necessary because they still have reasonable chances of having a natural pregnancy. ${ }^{37}$ Moreover, a minority of couples with severe reproductive disorders still conceive spontaneously after unsuccessful ART. ${ }^{38}$ In addition, the widespread concerns about conceiving twins and triplets after ART, and the increasing success rate of single embryo transfer, already have led or soon will lead to a reduction in multiple deliveries. Consequently, the boost of ART to TFRs caused by the high proportion of twin or triplet deliveries in the past has decreased. Adjusting for the proportion of couples who would have conceived without ART, and for the decline in twinning or triplet rates, Sobotka and co-workers ${ }^{39}$ estimate that only around 3\% of Danish women born in 1975-1978 have or will become mothers by virtue of ART instead of the $7 \%-8 \%$ often claimed. The vast majority of the rise in birth rates during the last decades in several EU countries is caused by the birth of naturally conceived children. The rise in Denmark is a spectacular example of this trend.

\footnotetext{
'The crucial question is whether semen quality among young men in Europe is now so low that it has reached a threshold at which fertility rates may be affected'. 'Younger Danish cohorts of women appeared to have progressively lower total natural conception rates. The results suggest a cohort-related decline in fecundity (ability to conceive)'

What is actually the relation between sperm parameters and male fecundity? The three characteristics from semen analysis widely accepted as surrogates for measuring male fecundity are sperm concentration, sperm motility and sperm morphology. Because assessing sperm concentration is a matter of relatively simple counting while sperm
}

morphology and motility are more sensitive to subjective judgement, sperm concentration (or count) is usually taken as the measure of male fecundity to monitor trends. Recently, it became evident that total sperm count - the product of ejaculate volume and sperm concentration-better reflects male reproductive potential than sperm concentration alone, provided abstinence times are carefully taken into account. ${ }^{40}$ As argued in a previous section, markers of semen quality are proxy measures of couple fecundity and one would expect that declining sperm quality directly corresponds with lower couple fecundity. Does it?

Since the large but unexplained geographical differences in sperm counts was a major problem for the interpretation of the results of the Carlsen paper, ${ }^{11} 27$ studies on time trends of sperm parameters in the same area or country were initiated after $1992 .{ }^{41}$ Six demonstrated a decline, 16 found no decline or an increase and five reported ambiguous results; consequently the debate was not resolved at all. These contradictory findings raised two fundamental questions: (i) are these regional differences caused by differences in methodology of sperm analysis tests or in subject recruitment? (ii) do these differences reflect differences in fecundity? These questions prompted an unprecedented, prospective and coordinated action in Finland, Denmark, Scotland and France in which sperm parameters were related to couple fecundity-almost 1000 couples took part. ${ }^{42-44}$ The results of the combined data of the four countries demonstrated an overall trend of a relation between increasing sperm concentrations up to about 50 million per $\mathrm{ml}$ with shorter times to pregnancy corresponding with better fecundity. However, the results also revealed that the relation between sperm concentration and couple fecundity was far from straightforward. For example, the average sperm count of Finnish men was considerably higher than that in the other countries, whereas Finnish couples appeared to be the least fecund. Apparently, differences or changes in sperm counts between regions and over time have to be interpreted with caution. Although there is a statistically significant relation between sperm characteristics and couple fecundity, this relation is rather weak. There are many more determinants of couple fecundity which have to be taken into account as argued in the previous section. In utero exposure of the male partner to endocrine disrupting chemicals - the major mechanism proposed by the authorsis just one of them.
'The increasing use of ART also indicates that infertility is growing'. 'Poor semen quality may be part of the reason for the increasing use of ART'

The availability of ART treatments in Denmark increased from $\sim 1400$ cycles per million inhabitants in 1997 to $\sim 2400$ in $2006,{ }^{18}$ making the Danish ART density the highest in Europe. To the authors of the Science Policy Briefing, this makes sense because in their opinion, male reproductive health is seriously endangered in this country. However, we think that the enormous increase in the number of IVF and intracytoplasmic sperm injection cycles, not only in Denmark but in most developed countries, is related to the notion of 'impatience to conceive' as introduced by Leridon. ${ }^{45} \mathrm{He}$ compared the results of two surveys on reproductive behaviour conducted in 1978 and 1988 - a period starting with the birth of the first IVF baby during which the miracles of reproductive technologies attained much public attention. He found that the subjective notion of 'difficulty in conceiving' considerably increased while the objectively assessed fecundity did not change. The same paradox was observed in the United States. ${ }^{21}$ The widespread availability of information about fertility, the public perception that IVF makes all the difference between fertility and sterility, the generally used one-year infertility definition suggesting that a couple is infertile in the sense of sterile if no pregnancy ensues within one year, justifying treatment thereafter, the growing number of couples who delay the decision of having children for years but once taken they want their baby rapidly, and the pressure of couples to have an IVF baby instead of, in their view, foolishly waiting endlessly for a natural conception, are all elements and attitudes at the base of this 'impatience to conceive' notion. Together with the illusion of deteriorating male reproductive health, they explain the enormous growth of the availability of fertility services and of the use of ART.

\section{CONCLUSION}

Are the serious concerns expressed in the Science Policy Briefing on male reproductive health justified? Intrauterine and postnatal influences related to our changing society and environment may adversely modify male and female fecundity. Since the publication of Carlsen's meta-analysis, ${ }^{11}$ there has been widespread anxiety about the negative impact of environmental pollutants on human reproduction. Given the well-known adverse effects of occupational exposures on reproduction in 
certain professions ${ }^{46}$ and the results of studies in wildlife where feminisation and sterility of male animals occur in highly polluted areas, ${ }^{47}$ the concern about adverse effects of environmental pollutants is not only understandable but fully warranted. However, the panic-stricken viewpoint of the authors of the Science Policy Briefing is not the appropriate approach to advance. In utero exposure of male foetuses to endocrine disruptors producing the testicular dysgenesis syndrome, the major mechanism proposed by Carlsen et al. in $1992^{11}$ and still embraced by the same group of authors in $2012,{ }^{18}$ is too limited. Changes in couple fecundity may also be caused by present exposures to environmental pollutants not only of the male but also of the female partner. In addition, changes in lifestyle related to smoking, stress, obesity, sexual behaviour and delay of childbearing may also adversely affect couple fecundity. These determinants have to be taken into account when addressing the impact of environmental pollutants. Moreover, the extreme pessimism and alarm expressed by the authors is based on some misconceptions.

'Whether the sperm concentration and human fecundity have declined during the past 50 years is a question we will probably never be able to answer'. This statement by Olsen and Rachootin in $2003^{48}$ still holds for sperm concentration despite the report in 1992. In the meantime, we know that the results of oft-repeated studies from Copenhagen and Malmö do not indicate any notable change in sperm count during the last 10-15 years. Moreover, none of the available evidence points to a decline in couple fecundity during the last $30-40$ years, including Denmark. ${ }^{28}$ Moreover, birth rates and TFRs instead of declining are on the increase in many EU countries, including the spectacular rise in Denmark. ${ }^{34}$

\section{COMPETING FINANCIAL INTERESTS}

All authors declare that there are no competing financial interests.

\section{ACKNOWLEDGMENTS}

We would like to thank the demographer Tomas Sobotka for valuable remarks.

1 ESF Science Policy Briefing 40; 2010. Male reproductive health-its impacts in relation to general wellbeing and low European fertility rates. http://www.esf.com
2 te Velde ER, Eijkemans R, Habbema HD. Variation in couple fecundity and time to pregnancy: an essential concept in human reproduction. Lancet 2000; 355 : 1928-9.

3 Bongaarts J. A method for the estimation of fecundability. Demography 1975; 12: 645-60.

4 Leridon H, Spira A. Problems in measuring the effectiveness of infertility therapy. Fertil Steril 1984; 41: 580-6.

5 Evers JL. Female subfertility. Lancet 2002; 360: 151-9.

6 Joffe M. Time to pregnancy: a measure of reproductive function in either sex. Asclepios Project Occup Environ Med. 1997; 54: 289-95.

7 Baird DD, Wilcox AJ, Weinberg CR. Use of time to pregnancy to study environmental exposures. Am J Epidemiol 1986; 124: 470-80

8 Joffe M, Key J, Best N, Keiding N, Scheike T et al. Studying time to pregnancy by use of a retrospective design. Am J Epidemiol 2005; 162: 115-24.

9 Bonde JP, Joffe M, Sallmen M, Kristensen P, Olsen J et al. Validity issues relating to time-to-pregnancy studies of fertility. Epidemiology 2006; 17: 347-9.

10 Habbema JD, Collins J, Leridon H, Evers JL, Lunenfeld $\mathrm{B}$ et al. Towards less confusing terminology in reproductive medicine: a proposal. Fertil Steril 2004; 82: 36-40.

11 Carlsen E, Giwercman A, Keiding N, Skakkebaek NE. Evidence for decreasing quality of semen during past 50 years. BMJ 1992; 305: 609-13.

12 Lerchl A, Nieschlag E. Decreasing sperm counts? A critical (re)view. Exp Clin Endocrinol Diabetes 1996; 104: 301-7.

13 Bonde JP, Ramlau-Hansen $\mathrm{CH}$, Olsen J. Trends in sperm counts. The saga continues. Epidemiology 2011; 5: 1-3.

14 Wilcox AJ. On sperm counts and data responsibility. Epidemiology 2011; 22: 1-2.

15 Axelsson J, Rylander L, Rignell-Hydbom A, Giwercman A. No secular trend over the last decade in sperm counts among Swedish men from the general population. Hum Reprod 2011; 26: 1012-6.

16 Jorgensen $N$, Vierula $M$, Jacobsen R, Pukkala $E$, Perheentupa $A$ et al. Recent adverse trends in semen quality and testis cancer among Finnish men. Int J Androl 2010; 34: e37-48.

17 Bonde JP, Jensen MS, Ramlau-Hansen CH, Toft GF, Thulstrup AM et al. Trends in sperm count in Finnish men. Int J Androl 2012; 35: 626.

18 Lassen TH, Sobotka T, Jensen TK, Jacobsen R, Erb S et al. Trend in rates of natural conceptions among Danish women during 1960-1984. Hum Reprod 2012; 27: 2815-22.

19 Joffe M. Time trends in biological fertility in Britain. Lancet 2000; 355: 1961-5.

20 Scheike TH, Rylander L, Carstensen L, Keiding N, Jensen TK et al. Time trends in human fecundability in Sweden. Epidemiology 2008; 19: 191-6.

21 Stephen EH, Chandra A. Declining estimates of infertility in the United States: 1982-2002. Fertil Steril 2006; 86: 516-23.

22 Graham H. Smoking prevalence among women in the European community 1950-1990. Soc Sci Med 1996; 43: 243-54.

23 te Velde ER, Pearson PL. The variability of female reproductive ageing. Hum Reprod Update 2002; 8: 141-54

24 Sartorius GA, Nieschlag E. Paternal age and reproduction. Hum Reprod Update 2009; 16: 65-79.

25 Homan GF, Davies M, Norman R. The impact of lifestyle factors on reproductive performance in the general population and those undergoing infertility treatment: a review. Hum Reprod Update 2007; 13: 209-23.

26 Sallmen M, Weinberg CR, Baird DD, Lindbohm ML, Wilcox AJ. Has human fertility declined over time? Why we may never know. Epidemiology 2005; 16: 494-9.
27 Templeton A, Fraser C, Thompson BHR. Infertility, epidemiology and referral practice. Hum Reprod $1991 ; 6:$ 1391-4.

28 Jensen TK, Joffe M, Scheike T, Skytthe A, Gaist D et al. Time trends in waiting time to pregnancy among Danish twins. Hum Reprod 2005; 20: 955-64.

29 Oakley L, Doyle P, Maconochie N. Lifetime prevalence of infertility and infertility treatment in the UK: results from a population-based survey of reproduction. Hum Reprod 2008; 23: 447-50.

30 Bhattacharya S, Porter M, Amalraj E, Templeton A, Hamilton $\mathrm{M}$ et al. The epidemiology of infertility in the North East of Scotland. Hum Reprod 2009; 24: 3096-107.

31 Olsen J, Zhu JL, Ramlau-Hansen CR. Has fertility declined in recentt decades? Ata Obstet Gyneacol Scand 2011; 90: 129-35.

32 van de Kaa DJ. Europe's second demographic transition. Popul Bull 1987: 42: 1-59.

33 Lesthaege R. The unfolding story of the second demographic transition. Popul Dev Rev 2010; 36: 211-51.

34 Goldstein JR, Sobotka T, Jasiloniene A. The end of "lowest-low" fertility. Popul Dev Rev 2009: 35 : 663-99.

35 European Demographic Data Sheets 2008 and 2010. Vienna Institute of Demography. http://www. oeaw.ac.at/vid/datasheet/index.htm

36 Myrkylä M, Kohler HP, Billari F. Advances in development reverse fertility decline. Nature 2009; 460: 741-3.

37 Habbema JD, Eijkemans MJ, Nargund G, Beets G, Leridon $\mathrm{H}$ et al. The effect of in vitro fertilization on birth rates in western countries. Hum Reprod 2009: 24: 1414-9.

38 Evers JLH, de Haas HW, Land JA, Dumoulin JCM, Dunselman GA. Treatment-independent pregnancy rate in patients with severe reproductive disorders. Hum Reprod 1998; 13: 1206-9.

39 Sobotka T, Hansen MA, Jensen TK, Pedersen AT, Lutz $W$ et al. The contribution of ART to the completed fertility: an analysis of Danish data. Popul Dev Rev 2008; 34: 79-101.

40 Cooper TG, Noonan E, von Eckardstein S, Auger J, Baker HW et al. World Health Organization reference values for human semen characteristics. Hum Reprod Update 2010; 16: 231-45.

41 Fisch $H$. Declining worldwide sperm counts: disproving a myth. Urol Clin North Am 2008; 35 : 137-46.

42 Jensen TK, Slama R, Ducot B, Suominen J, Cawood $\mathrm{EH}$ et al. Regional differences in waiting time to pregnancy among fertile couples from four European cities. Hum Reprod 2001; 16: 2697-704.

43 Jorgensen N, Andersen AG, Eustache F, Irvine DS, Suominen $\mathrm{J}$ et al. Regional differences in semen quality in Europe. Hum Reprod 2001; 16: 1012-9.

44 Slama R, Eustache F, Ducot B, Jensen TK, Jorgensen $\mathrm{N}$ et al. Time to pregnancy and semen parameters: a cross-sectional study among fertile couples from four European cities. Hum Reprod 2002; 1: 503-15.

45 Leridon H. Sterility and subfecundity: from silence to impatience? Population (English Version) 1992; 4: 35-54.

46 Burdorf A, Figa-Talamanca I, Jensen TK, Thulstrup AM. Effects of occupational exposure on the reproductive system: core evidence and practical implications. Occup Med (Lond) 2006; 56: 516-20.

47 Edwards TM, Moore BC, Guillette LJ. Reproductive dysgenesis in wildlife: a comparative view. Int $J$ Androl 2006; 29: 109-21.

48 Olsen J, Rachootin P. Invited commentary: monitoring fecundity over time - if we do it, then let's do it right. Am J Epidemiol 2003; 157: 94-7.

49 Sobotka T, Skirkkbek V, Phillipov D. Economic recession and fertility in the developed world. Popul Dev Rev 2011; 37: 267-306. 